\title{
Identification of genes involved in induction of plant hypersensitive cell death
}

\author{
Takashi Kaneda ${ }^{1}$, Satsuki Fujiwara ${ }^{1}$, Ryota Takai ${ }^{1}$, Seiji Takayama ${ }^{1}$, Akira Isogai ${ }^{1}$, \\ Fang-Sik Che $\mathrm{C}^{1,2, *}$ \\ ${ }^{1}$ Graduate School of Biological Sciences, Nara Institute of Science and Technology, Ikoma, Nara 630-0192, Japan; \\ ${ }^{2}$ Department of Environmental Biology, Faculty of Bio-Science, Nagahama Institute of Bio-Science and Technology, \\ 1266 Tamura-cho, Nagahama, Shiga, 526-0829, Japan \\ *E-mail: k_sai@nagahama-i-bio.ac.jp
}

Received October 25, 2006; accepted December 8, 2006 (Edited by T. Kohchi)

\begin{abstract}
The hypersensitive response (HR) is a form of programmed cell death commonly associated with immune response in plants. Incompatible N1141 strain of Acidovorax avenae elicits HR cell death in cultured rice cells, while flagellin-deficient N1141 mutant ( $\Delta$ fla-N1141) lost the ability to induce immune responses. We present evidence that initiation of HR cell death induced by the incompatible N1141 strain requires de novo protein synthesis. The protein kinase inhibitors, staurosporine and K252a, effectively suppressed HR cell death, while the protein phosphatase inhibitors, calyculin A and okadaic acid, did not affect the induction of HR cell death. To identify the key initiator of HR cell death, PCR subtraction analysis and microarray analysis were performed. PCR subtraction analysis identified 42 genes which are induced during HR cell death, and microarray analysis (22K) showed that 87 genes were induced during HR cell death. Among identified genes, OSNAC gene encoding plant specific transcription factor was identified in both analyses. Real-time reverse-transcription PCR analysis for several OsNAC family genes revealed that OsNAC4 gene was strongly and specifically induced during HR cell death in cultured rice cells. Results showed that OsNAC4 transcription factor is an influential candidate as a key initiator in plant HR cell death.
\end{abstract}

Key words: Acidovorax avenae, microarray, hypersensitive cell death, plant immune response, rice (Oryza sativa).

Plants are exposed to a variety of potential pathogens during their lifetime, but actual infection only occurs in limited cases. Aside from preformed physical and chemical barriers that prevent infection, a wide variety of immune responses are induced only after pathogen attack (Agrios 1997; Heath 2000; Nimchuk and Eulgem 2003). The earliest responses activated after host plant recognition include the oxidative burst, in which levels of reactive oxygen species (ROS) rapidly increase (Bolwell et al. 1995; Lamb and Dixon 1997), hypersensitive cell death (Greenberg 1997), crosslinking of cell wall proteins (Corbin et al. 1987), activation of protein kinases (Romeis 2001), production of various plant protectants (Dixon et al. 1994), and expression of defense genes (Dixon et al. 1994). One of the most efficient and immediate immune response is the hypersensitive response (HR) cell death. The HR cell death is characterized by rapid, local death of plant cells at the sites of pathogen infection and is a common feature of incompatible plantpathogen interactions (Greenberg 1997; Dangl and Jones 2001; Lam, 2004). The HR thus confines the pathogen by stopping it from spreading from the site of potential infection.

The HR cell death requires active plant metabolism and depends on the activity of transcriptional and translational machinery in the host plant (He 1996; Mittler and Lam 1996; Morel and Dangl 1997; Pennell and Lamb, 1997; Glichrist 1998; Gray and Johal 1998; Heath 1998; Richberg et al. 1998). Induction of HR cell death is associated with certain signaling events such as protein phosphorylation and generation of ROS (Jabs et al. 1996; Levin et al. 1996; Alvarez et al. 1998). Furthermore, the overexpression of certain transgenes in plants can lead to the spontaneous activation of hypersensitive cell death in the absence of pathogens (Dietrich et al. 1997; Richberg et al. 1998). All of these lines of evidence suggest that the HR cell death is a form of programmed cell death, as its initiation depends on active plant metabolism. The HR cell death is characterized by a number of hallmark cytological and biochemical features, including a distinct cellular morphology, such as plasma membrane shrinkage and condensation (Che et al. 1999; Lacomme and Santa 1999), and production of characteristic DNA

Abbreviations: Cy3, cyanine 3; Cy5, cyanine 5; HR, hypersensitive response; PCR, polymerase chain reaction.

This article can be found at http://www.jspcmb.jp/ 
fragmentation resulting from the inter-nucleosomal cleavage of nuclear DNA (Tanaka et al. 2001; Yao et al. 2001). These HR cell death responses have been considered to be a form of animal cell apoptosis (Gilchrist 1998; Xu and Roossinck 2000; Greenberg and Yao 2004). In spite of several morphological and biochemical similarities between plant HR cell death and animal cell apoptosis, plant HR cell death has important differences from the process of apoptosis of animal cells at several levels. At the morphological level, apoptotic bodies that are phagocytosed by other cells are not formed during plant HR cell death, because of the presence of the cell wall. At the genetic level, whole genome sequencing of plants has revealed that the plant genome does not contain any obvious homologues to the key animal apoptosis proteins, such as the Bcl-2 family protein (Kutuk and Basaga 2006) and caspase (Shi 2002). These findings indicate that plant HR cell death is induced by the mechanism different from that of apoptosis. However, little is known about the molecular mechanism of the HR cell death program.

Acidovorax avenae is a Gram-negative bacterium that causes a seedling disease characterized by the formation of brown stripes on the sheaths of infected plants (Kadota et al. 1991). The species of $A$. avenae can infect a wide range of monocotyledonous plants including rice, oats, Italian millet and maize. However, individual strains of the pathogen infect only one or a few host species (Nishiyama et al. 1979; Kadota et al. 1991; Kadota et al. 1996). We recently reported that a riceincompatible strain such as A. avenae N1141 caused several immune responses including rapid cell death, oxidative burst, and induction of several immunityrelated genes, while rice-compatible strains such as H8301 or K1 did not. Furthermore, purified N1141 flagellin, a component of the flagellum filament of bacteria, also induced immune responses in cultured rice cells, and a flagellin-deficient N1141 mutant lacked the ability to induce immune responses, showing that the flagellin from the incompatible strain of $A$. avenae functions to elicit immune responses (Che et al. 2000). The rapid death in cultured rice cells induced by the incompatible N1141 strain was accompanied clear by 180-bp nucleosomal DNA laddering and typical morphological change such as plasma membrane shrinkage and nuclear condensation (Che et al. 2000; Tanaka et al. 2001), suggesting that the rapid cell death in cultured rice cells induced by the incompatible N1141 strain of A. avenae is HR cell death which possesses all features characterized in other plants. Suspension cultured cells present the advantage of being relatively homogenous and are useful for profiling of short-term biological modification after pathogen or elicitor recognition because all cells are exposed to the pathogen or elicitors at the same time (Akimoto-Tomiyama et al.
2003). These observations indicate that our experimental systems which combine cultured rice cells with $A$. avenae or its flagellin-deficient mutant provide excellent models for studies of the induction mechanism of HR cell death in rice.

In this study, we identified genes which are expressed during HR cell death using PCR-based subtractive hybridization. To confirm whether the identified genes truly are specifically expressed during HR cell death, we further analyzed the gene expression profiles during HR cell death using a $22 \mathrm{~K}$ oligo-microarray. The results showed that 87 genes on the array, including transcription factor genes and defense-related genes, were specifically expressed during HR cell death. Several genes are identified by both analytic methods, PCR-subtraction and microarray. These novel identified genes are candidates as initiation factors in the HR cell death.

\section{Materials and methods}

\section{Plants and bacteria}

Suspension cultures of rice cells, line Oc (Baba et al. 1986), were grown at $30^{\circ} \mathrm{C}$ under light irradiation. Cells were diluted with fresh medium every 7 days, and all experiments were performed 4 days after transfer. The $A$. avenae N1141 strain (MAFF 301141), isolated from finger millet, was utilized as previously described (Kadota et al. 1996; Che et al. 2000). The $\Delta$ fla-N1141 (flagellin-deficient N1141 strain) was used as previously described (Che et al. 2000). Each A. avenae strain was maintained at $30^{\circ} \mathrm{C}$ on Pseudomonas $\mathrm{F}$ agar plates (Difco, USA) as described (Che et al. 1999).

\section{PCR subtraction analysis}

Following incubation with each bacterial strain $\left(10^{8} \mathrm{cfu} \mathrm{m}^{-1}\right)$ or purified flagellin $\left(25 \mu \mathrm{g} \mathrm{ml}^{-1}\right.$ ) (or water as a control), RNA was isolated from the cultured rice cells. Total RNA was isolated from cultured rice cells using ISOGEN reagent (Nippon Genes, Japan). Poly $\mathrm{A}^{+}$RNA fractions from both the tester and driver samples were isolated using Micro-FastTrack 2.0 mRNA isolation kit (Invitrogen, USA). Both first-strand cDNAs were synthesized and then digested with RsaI. PCRsubtraction was performed with cells inoculated with N1141 strains as a driver and flagellin-deficient N1141 mutantinoculated cells as a tester according to the manufacturer's protocol (PCR-Selected cDNA Subtraction kit; Clontech). A driver-specific subtracted cDNA pool was cloned into the pCR2.1 TA vector (Invitrogen). The cDNA clones showing differential expression were subjected to sequencing reactions using the BigDye terminator sequencing kit Ver 3.1 (Applied BioSystems, Foster City, CA, USA) and ABI Model 3100 DNA Analyzer (Applied BioSystems). The database search was performed on the basis of the cDNA sequences using BLASTX and BLASTN. BLASTN was used in the event of absence of any matched hits when BLASTX was used.

\section{K oligo-Microarray analysis}

We used the long oligonucleotide array (60-mer; Agilent Technologies, 22K) designed based on tentative consensus 
sequences from the Institute for Genomic Research. Following incubation with $\mathrm{N} 1141$ and $\Delta$ fla-N1141 (flagellin-deficient N1141 strain), cultured rice cells were ground in liquid nitrogen. Total RNA was extracted with ISOGEN (Nippongene, Tokyo, Japan). All microarray procedures were performed according to the manufacturer's protocol (Agilent Technologies). cRNAs were synthesized from $500 \mathrm{ng}$ of total RNA for each biological replicate with T7 promoter primer. Synthesized cRNA was further labeled with $\mathrm{Cy} 3$ or $\mathrm{Cy} 5$ dye molecule. Labeled probes were purified with RNeasy kit (QIAGEN, Hilden, Germany) according to the manufacturer's protocol, and treated with $240 \mu \mathrm{l}$ of Target Solution (Agilent Technologies). After incubating at $60^{\circ} \mathrm{C}$ for $30 \mathrm{~min}, 204 \mu \mathrm{l}$ of Hybridization Buffer was added to the probe solutions, and samples were centrifuged at $15,000 \mathrm{~g}$ for $5 \mathrm{~min}$ to remove any particulate matter. The probes were placed onto the center of the array to avoid bubble romation. A cover slip was placed over the entire array surface also to avoid bubble formation. Slides were placed in a sealed hybridization cassette and incubated in a hybridization incubator (Agilent Technology) at $60^{\circ} \mathrm{C}$ for $17 \mathrm{~h}$. After hybridization, slides were soaked in washing solution 1 ( $6 \times \mathrm{SSPE}$ and $0.005 \% \mathrm{~N}$-Lauroylsarcosine), and were tilted down to remove the cover glass. The slides were placed into slide racks and plunged up and down three times in washing solution 1 at $37^{\circ} \mathrm{C}$ for $1 \mathrm{~min}$. The slides were transferred to Agilent Stabilization and Drying Solution at $37^{\circ} \mathrm{C}$ for $10 \mathrm{sec}$, and dried in a dry box. Microarrays were scanned with a scanning laser microscope, model ScanArray4000XL (GSI Lumonics, Billerica, MA, USA). Separate images were acquired for each fluor at a resolution of $10 \mu \mathrm{m}$ per pixel. For microarray data analysis, we used ArrayVision 5.1 (Amersham) and GeneSpring 5.0 (Silicon Genetics, Redwood, CA, USA). Local background was subtracted from the value of each spot on the array. Spots covered by dust particles, missing spots, spots with low signal intensity, and spots in high background areas were flagged as candidates for exclusion after further analysis. Normalization between the $\mathrm{Cy} 3$ and $\mathrm{Cy} 5$ fluorescent dye emission channels was achieved by calculating the ratio between total Cy3 signals from all spots in relation to total Cy5 signals from all spots.

\section{Microarray data analysis}

For microarray data analysis, we used ImaGene version 5.1 (BioDiscovery, Los Angeles, CA, USA) and GeneSpring 5.0 (Silicon Genetics, Redwood, CA, USA). Local background was subtracted from the value of each spot on the array. Spots covered by dust particles, missing spots, spots with low signal intensity, and spots in high background areas were flagged as candidates for exclusion after further analysis. Normalization between the $\mathrm{Cy} 3$ and $\mathrm{Cy} 5$ fluorescent dye emission channels was achieved by calculating the ratio between total Cy3 signal from all spots in relation to total Cy5 signal from all spots (Hardwick et al. 1999).

\section{Real-time RT-PCR analysis}

Expression profiles of selected genes were analyzed by realtime RT-PCR analysis using the QuantiTect SYBR Green RTPCR kit (QIAGEN, Hilden, Germany). Cultured rice cells was inoculated with N1141 or $\Delta$ fla1141-2 $\left(10^{8} \mathrm{cfu} \mathrm{ml}^{-1}\right)$ (Tanaka et al. 2003). Ten nanograms of total RNA prepared from N1141 or $\Delta$ fla1141-2 inoculated cultured rice cells and the specific primer sets targeting $150 \mathrm{bp}$ of each gene were used. Real-time RT-PCR was performed according to the manufacturer's protocol (QuantiTect SYBR Green RT-PCR kit, QIAGEN), and the reaction was monitored using the ABI PRISM 7700 sequence detection system (Amersham Biotech). Fluorescence data produced sigmoidal-shaped amplification plots, in which the number of cycles was plotted against fluorescence. Quantification of each mRNA was calculated from threshold points located in the log-linear range of RT-PCR. Standard samples with known template amounts were used for quantification of PCR products.

\section{Results}

\section{Participation of protein synthesis and phosphorylation in HR cell death in cultured rice cells}

To assess whether HR cell death induced by the incompatible N1141 strain requires transcriptional activation or protein synthesis, HR cell death in cultured rice cells was measured $10 \mathrm{~h}$ after inoculation of N1141 strain in the absence or presence of cycloheximide $(5 \mu \mathrm{M})$. In the absence of cycloheximide, cell death induced by the incompatible N1141 strain of $A$. avenae was detected $4 \mathrm{~h}$ after inoculation, and the number of dead cells gradually increased. Conversely, the HR cell death was completely blocked by treatment with cycloheximide $(5 \mu \mathrm{M})$ for up to $10 \mathrm{~h}$ after inoculation (Figure 1). During this experimental period growth rates of bacteria were the same in the absence and presence of $5 \mu \mathrm{M}$ cycloheximide (data not shown). These data indicate that the HR cell death depends on de novo protein synthesis.

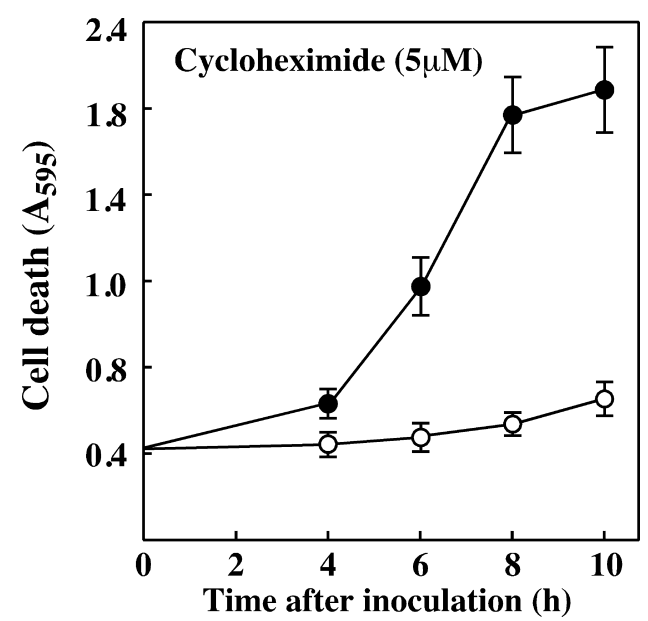

Figure 1. Effects of cycloheximide on induction of HR cell death in cultured rice cells. Time-course of cell death in cultured rice cells induced by the incompatible N1141 strain of $A$. avenae in the presence (open circles) and absence (solid circles) of cycloheximide $(5 \mu \mathrm{M})$. Degree of cell death was estimated by Evans blue staining of individual cells at Abs. $595 \mathrm{~nm}$. Each data point is the average of three independent experiments. Bars show standard errors. 
A

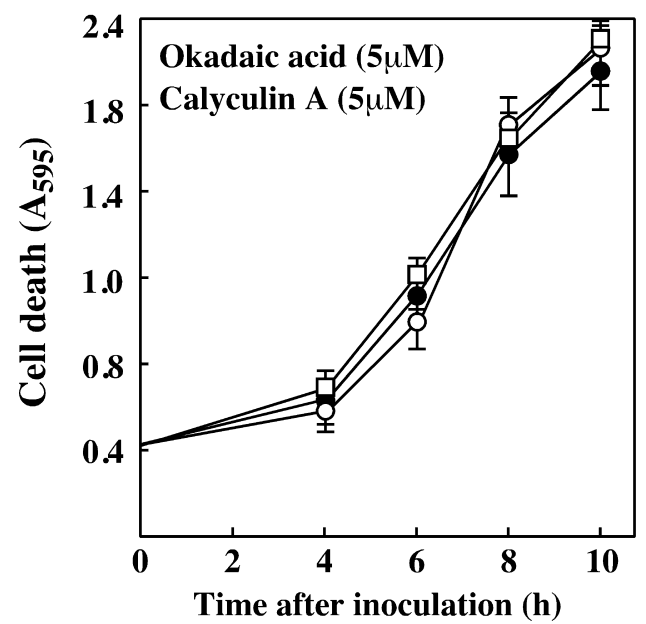

B

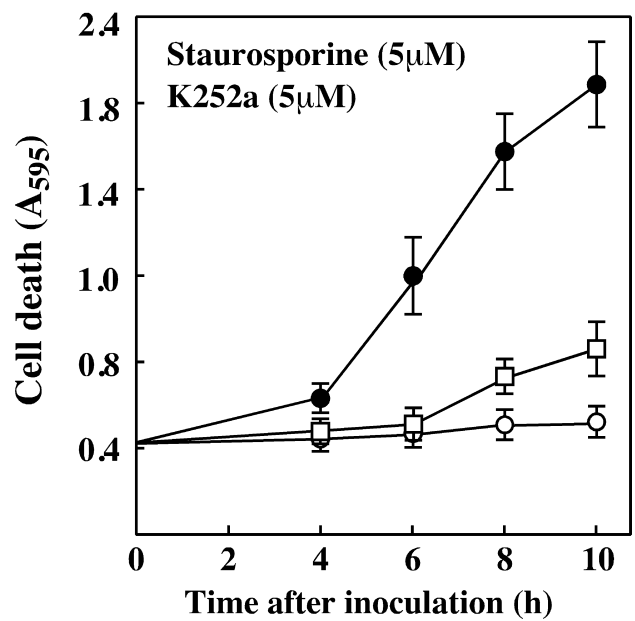

Figure 2. Effects of protein phosphatase and kinase inhibitors on N1141 induced HR cell death in cultured rice cells. (A) Time-course of cell death in cultured rice cells induced by the incompatible N1141 strain of $A$. avenae in the presence of $5 \mu \mathrm{M}$ okadaic acid (open circles), presence of $5 \mu \mathrm{M}$ calyculin A (open squares), and absence of inhibitor (solid circles). (B) Time-course of cell death in cultured rice cells induced by the incompatible $\mathrm{N} 1141$ strain of $A$. avenae in the presence of $5 \mu \mathrm{M}$ Staurospolin (open circles), presence of $5 \mu \mathrm{M} \mathrm{K} 252 \mathrm{a}$ (open square) and absence of inhibitor (solid circles). Degree of cell death was estimated by Evans blue staining of individual cells at Abs. $595 \mathrm{~nm}$. Each data point is the average of three independent experiments. Bars show standard errors.

Protein phosphorylation cascades are known to be involved in plant intracellular signaling pathways (Torii 2000). For example, elicitor treatment was shown to induce protein phosphorylation in cultured rice cells (Zhang et al. 2002). To determine whether induction of HR cell death in cultured rice cells is involved in protein phosphorylation signaling, effects of several protein phosphorylation inhibitors were examined. Calyculin A and okadaic acid, potent inhibitors of serine/threonine phosphatases type 1 and type 2A from both animals and plants, did not inhibit HR cell death induced by the incompatible N1141 strain (Figure 2A). In contrast staurosporin and K252a, potent inhibitors of plant and animal serine/threonine protein kinases, effectively suppressed HR cell death in cultured rice cells (Figure 2B). HR cell death in cultured rice cells induced by N1141 strain was greatly reduced, but not completely blocked in the presence of $5 \mu \mathrm{M}$ of $\mathrm{K} 252 \mathrm{a}$, while $5 \mu \mathrm{M}$ of staurosporin completely inhibited the induction of HR cell death (Figure 2B). Treatment with the inhibitors at used concentrations did not affect growth rates of bacteria during the experimental period. These data suggest the likely involvement of protein phosphorylation in the early stage of HR cell death induced by the incompatible N1141 strain.

\section{Identification of genes involved in HR cell death using PCR-subtraction}

Our results obtained using the several inhibitors together with other evidence indicate that induction of HR cell death requires de novo protein synthesis regulated by protein phosphorylation (Figure 1,2): genes specifically expressed during HR cell death is involved in initiation and execution of HR cell death. To determine these genes involved in HR cell death, we attempted identification of genes differentially expressed in HR cell death inducing rice cells and non HR cell death inducing rice cells using PCR subtraction. We recently reported that the incompatible N1141 strain caused rapid HR cell death in cultured rice cells, whereas flagellin-deficient mutant N1141 strain ( $\Delta$ fla-N1141) did not (Che et al. 2000). Therefore, PCR subtraction was performed for identification of HR cell death inducing factor for comparison between cultured rice cells inoculated with N1141 and $\Delta$ fla-N1141 strains.

mRNA samples were prepared from cultured rice cells $1 \mathrm{~h}, 3 \mathrm{~h}$ and $6 \mathrm{~h}$ after the inoculation with either N1141 or $\Delta$ fla-N1141 strain, and cDNAs were then synthesized from these samples. cDNA from $\Delta$ fla-N1141 inoculated cultured rice cells was subtracted from the cDNA from N1141 inoculated cultured cells for each time point. We isolated 31 clones from cultured rice cells after $1 \mathrm{~h}$ of inoculation, 106 clones after $3 \mathrm{~h}$ of inoculation, and 70 clones after $6 \mathrm{~h}$ of inoculation. All isolated clones were sequenced, and sequence homologies were found with the GenBank/EMBL database using the BLAST program. Sequence and homology analysis revealed that 42 cDNA clones were unique (average insert size, 420 bp) (Table 1). cDNAs were classified based on predicted function into 22 categories according to the MIPS Arabidopsis database (MAtDB; http://mips.gsf.de/proj/ thal $/ \mathrm{db}$ ). Approximately $22 \%$ of the sequences obtained from the subtraction have unknown function. More abundant transcripts in the cDNAs are involved in cell 
Table 1. Identification of cDNA clones

\begin{tabular}{llllll}
\hline Clone & Accession & \multicolumn{1}{c}{ Identification } & Clone & Accession & \multicolumn{1}{c}{ Identification } \\
\hline 1C01 & BI810617 & Expressed protein & 3B01 & BI118782 & Unknown expressed protein \\
1F04 & AB028185 & OsNAC6 & 3F05 & C98091 & Leucine zipper protein \\
1H04 & AU029644 & Flavohemoprotein b5/b5R & 3H08 & D64038 & EL2 protein \\
2A05 & BI811333 & ATP/ADP translocator & 4B10 & AU108431 & Cytoplasmic aconitate hydratase \\
2D08 & AP003215 & Protein kinase & 4D04 & AU081296 & Pyruvate kinase \\
2G08 & BE039993 & Ribosomal protein & 4D07 & AU197256 & Nodulin-like protein \\
2G09 & AU183579 & Lipid transfer protein & 4F01 & C97547 & Unknown expressed protein \\
2H10 & AU184271 & Dihydroorotate dehydrogenase & 4F02 & AU071201 & Unknown expressed protein \\
2H11 & D46264 & Calnexin-like protein & 4F06 & U54702 & Oryzacystatin \\
1C10 & BI1 18808 & RAD23 protein & 4F08 & BI806950 & Kinesin \\
1F11 & AP003271 & Ankyrin protein & 4F10 & AF394545 & Alpha-expansin \\
1H01 & BM420847 & 3-keto-acyl-CoA synthase & 4F11 & AB026731 & Dehydroascorbate reductase \\
2A12 & BM419777 & SEU1 protein(1e-09) & 4G08 & AU108269 & 14-3-3 protein \\
2B12 & D22233 & Amino acid permease & 4H04 & AB067653 & Peptide transporter \\
C04 & BE228915 & Subtilisin-chymotrypsin inhibitor 2 & 1B01 & AU030252 & Thioredoxin protein \\
2D02 & BI813763 & Unknown expressed protein & 2C01 & AU162696 & Methionine synthase protein \\
2D10 & AU184575 & Unknown expressed protein & 2F08 & BI118686 & MAP kinase homolog protein \\
2D11 & BE039613 & Elongation factor 1 & 3B05 & AB028183 & OsNAC4 \\
3A06 & D31843 & Plasma membrane H+-ATPase & 3F04 & BE607391 & Metallothionein-like protein \\
3A07 & AJ427979 & Potasium transporter & 4H07 & AP003922 & Unknown expressed protein \\
3A08 & BF430788 & Peptidylprolyl isomerase & 4H07 & AP003922 & Unknown expressed protein
\end{tabular}

The table gives the identification of the cDNA clones using blast analysis

The initial number of each clone correspond to time after inoculation gainst EMBL/NCBI database

rescue, defense, cell death and ageing (16\%), metabolism $(12 \%)$, cellular communication and signal transduction $(10 \%)$, and cellular transport and transport mechanisms (7\%). Among these genes, we found some genes already known to be involved in plant immune response, e.g., EL2 (D64038), thioredoxin (AU030252) and MAPK (BI118686). In addition, only two genes encoding transcription factor, OSNAC4 and OsNAC6, were included in these cDNAs.

\section{Gene expression profile of cultured rice cells treated with $N 1141$ or $\Delta$ fla-N1141}

It was known that there were a number of false positive clones even with the end point of the PCR subtraction process. In order to eliminate false positive clones and to identify more genes involved in the induction of HR cell death, an additional microarray analysis was performed. Cultured rice cells were inoculated with N1141 strain or $\Delta$ fla-N1141 strain for $0,1,3$ and $6 \mathrm{~h}$, and mRNAs from inoculated and control cells (water treated cells) were used as probes for microarray analysis. Labeled cDNAs prepared from the cultured rice cells inoculated with either N1141 or $\Delta$ fla-N1141 were hybridized along with control cDNAs prepared from water-treated cultured rice cells. Microarray analysis was performed twice for each experiment using RNAs prepared from three different biological samples. The Cy3/Cy5 signal intensities were adjusted based on the total $\mathrm{Cy} 3$ signal from all spots in relation to the total Cy5 signal. After quantitation of the signal intensities and normalization, we identified genes which showed significant differences in expression during N1141 and $\Delta$ fla-N1141 interactions using multiple testing correction (Benjamini and Hochberg False
Discovery Rate, 0.01). In addition, we applied a 3-fold expression cutoff to make the selection more stringent during the incompatible interactions. Of 22,000 spotted genes, 2,386 were selected as responsive to inoculation with the incompatible N1141 strain. Among these genes, 1,184 were upregulated by inoculation with N1141 and 1,202 were down regulated by its inoculation. These results indicated that these genes are likely to be involved in the early events of HR cell death. To determine HR cell death related genes, expression profiles of the 1,184 genes upregulated during the incompatible interaction were compared between N1141 and flagellin-deficient N1141 mutant, $\Delta$ fla-N1141 (HR-non inducible strain), interactions. A $t$-test revealed that 87 genes showed significant differences in expression between N1141 and $\Delta$ fla-N1141 interactions (Table 2).

Among the identified genes, approximately $46 \%$ of transcripts were classified as encoding proteins of unknown function (Table 2). The transcripts upregulated during HR cell death included genes with sequence identity with Ser/Thr protein kinase, EF-hand $\mathrm{Ca}^{2+}$ binding protein, cytochrome $\mathrm{P} 450$, thioredoxin, defenserelated Mlo9, hexokinase 1 and HR induced response protein. Interestingly, we found several genes that encoded plant transcription factors such as OsNAC4, OsNAC3, G-box binding factor 1 and $\mathrm{C} 2 \mathrm{H} 2$ zinc finger protein (Table 2). Among these transcription factorencoding genes, OSNAC4 gene was obtained from both microarray and PCR subtraction analyses (Table 1 and Table 2). This finding suggests that OsNAC4 is one of the important factors for induction of HR cell death.

NAC proteins constitute one of the largest families of plant-specific transcription factors, and the family is 
Table 2. Identification of differentially expressed transcripts between cultured rice cells inoculated with the incompatible N1141 and Dfla-N1141 strains at different time points.

\begin{tabular}{|c|c|c|c|c|c|c|c|c|c|}
\hline \multirow{2}{*}{ Accession } & \multicolumn{4}{|c|}{$\Delta$ fla-N1141 } & \multicolumn{4}{|c|}{ N1141 } & \multirow{2}{*}{ Putative gene identification } \\
\hline & $0 \mathrm{~h}$ & $1 \mathrm{~h}$ & $3 \mathrm{~h}$ & $6 \mathrm{~h}$ & $0 \mathrm{~h}$ & $1 \mathrm{~h}$ & $3 \mathrm{~h}$ & $6 \mathrm{~h}$ & \\
\hline AK100678 & 1.2 & 2.5 & 15.0 & 32.2 & 1.2 & 4.6 & 75.5 & 103.1 & Decarboxylase 1 \\
\hline AK067848 & 1.1 & 1.3 & 2.0 & 2.1 & 1.1 & 2.0 & 9.0 & 4.6 & Unknown expressed protein \\
\hline AK107276 & 1.1 & 1.3 & 2.9 & 16.6 & 1.1 & 2.9 & 12.8 & 52.4 & Unknown expressed protein \\
\hline AK099563 & 1.1 & 1.2 & 10.8 & 19.2 & 1.1 & 4.0 & 14.7 & 56.2 & Unknown expressed protein \\
\hline AK068177 & 1.2 & 1.6 & 3.8 & 5.2 & 1.2 & 2.0 & 5.0 & 29.0 & Unknown expressed protein \\
\hline AK106672 & 0.7 & 1.1 & 11.1 & 24.3 & 0.7 & 2.4 & 12.2 & 45.7 & Lol-83 cytochrome P450 \\
\hline AK066000 & 0.9 & 1.1 & 3.6 & 10.3 & 0.9 & 2.1 & 6.5 & 21.5 & Serine/threonine protein kinase isolog \\
\hline AK072982 & 1.1 & 1.5 & 12.1 & 18.6 & 1.1 & 8.1 & 16.2 & 51.5 & Unknown expressed protein \\
\hline AK058853 & 1.1 & 2.1 & 3.4 & 3.5 & 1.1 & 1.7 & 7.3 & 10.1 & Unknown expressed protein \\
\hline AK109278 & 1.2 & 1.3 & 5.7 & 6.2 & 1.2 & 4.1 & 22.2 & 42.4 & EF-hand $\mathrm{Ca} 2+$-binding protein $\mathrm{CCD} 1$ \\
\hline AK068861 & 1.0 & 0.9 & 3.1 & 11.9 & 1.0 & 2.7 & 3.4 & 21.8 & $\mathrm{C} 2 \mathrm{H} 2$ zinc finger protein \\
\hline AK069098 & 1.0 & 1.4 & 3.0 & 7.7 & 1.0 & 2.0 & 9.8 & 15.1 & Ramy1 (ramy1) \\
\hline AK063578 & 1.1 & 1.2 & 3.4 & 14.8 & 1.1 & 2.3 & 8.1 & 44.3 & ABA-responsive protein \\
\hline AK063334 & 0.9 & 1.1 & 7.4 & 65.2 & 0.9 & 5.1 & 90.4 & 285.3 & Protein phosphatase 2C \\
\hline AK073848 & 1.0 & 1.2 & 4.2 & 6.2 & 1.0 & 3.6 & 79.3 & 67.6 & OsNAC4 protein \\
\hline AK111571 & 1.0 & 1.2 & 5.0 & 4.8 & 1.0 & 4.4 & 3.0 & 11.4 & Syringolide-induced protein 1-3-1B \\
\hline AK108158 & 0.9 & 0.8 & 2.5 & 4.7 & 0.9 & 2.8 & 2.1 & 15.6 & Unknown expressed protein \\
\hline AK063677 & 1.2 & 0.9 & 2.2 & 16.5 & 1.2 & 3.1 & 2.7 & 50.9 & Em protein \\
\hline AK067690 & 1.1 & 0.8 & 2.2 & 2.4 & 1.1 & 2.2 & 2.9 & 5.1 & OsNAC3 protein \\
\hline AK061237 & 1.2 & 0.6 & 2.3 & 4.9 & 1.2 & 2.2 & 3.2 & 11.7 & Unknown expressed protein \\
\hline AK067214 & 0.9 & 1.2 & 6.2 & 24.4 & 0.9 & 5.3 & 16.3 & 48.7 & Pollen allergen Jun o 4 \\
\hline AK100279 & 1.0 & 0.8 & 2.3 & 3.5 & 1.0 & 1.4 & 4.9 & 7.6 & RSH-like protein \\
\hline AK070333 & 1.0 & 1.4 & 2.0 & 2.2 & 1.0 & 1.9 & 3.3 & 6.0 & Mpc5 protein phosphatase-2C ( $\mathrm{PP} 2 \mathrm{C})$ \\
\hline AK063538 & 0.9 & 1.2 & 3.6 & 9.9 & 0.9 & 1.5 & 4.0 & 28.7 & Unknown expressed protein \\
\hline AK070872 & 1.0 & 0.7 & 1.9 & 6.4 & 1.0 & 1.1 & 7.0 & 15.1 & blt101 \\
\hline AK111091 & 1.1 & 0.8 & 2.6 & 4.3 & 1.1 & 3.0 & 1.5 & 14.1 & Unknown expressed protein \\
\hline AK102039 & 1.1 & 1.3 & 1.8 & 17.5 & 1.1 & 2.1 & 8.4 & 94.0 & Hydrophobic LEA-like protein \\
\hline AK107168 & 0.9 & 1.2 & 4.3 & 5.8 & 0.9 & 2.5 & 1.9 & 15.2 & NPK1-related protein kinase \\
\hline AK065440 & 1.0 & 0.7 & 2.1 & 3.2 & 1.0 & 1.6 & 9.2 & 8.5 & G-box binding factor 1 (GBF1) \\
\hline AK102686 & 1.0 & 0.9 & 3.4 & 11.4 & 0.9 & 1.0 & 13.9 & 43.0 & Rtac1 \\
\hline AK062978 & 1.0 & 1.3 & 2.8 & 6.7 & 1.0 & 1.8 & 4.9 & 14.1 & Unknown expressed protein \\
\hline AK099529 & 1.0 & 0.9 & 2.0 & 4.4 & 1.0 & 3.2 & 2.0 & 12.4 & Arm repeat-containing protein \\
\hline AK108264 & 1.0 & 0.8 & 2.0 & 5.7 & 1.0 & 0.7 & 8.0 & 19.7 & Unknown expressed protein \\
\hline AK065588 & 1.0 & 1.1 & 1.8 & 5.6 & 1.0 & 1.3 & 4.7 & 11.9 & Unknown expressed protein \\
\hline AK063517 & 1.1 & 0.9 & 1.2 & 13.4 & 1.1 & 1.2 & 9.5 & 76.8 & Dehydrin \\
\hline AK103708 & 0.8 & 0.8 & 2.2 & 2.7 & 0.8 & 1.2 & 4.2 & 5.8 & Unknown expressed protein \\
\hline AK067659 & 1.0 & 1.2 & 0.9 & 2.1 & 1.0 & 1.0 & 2.3 & 4.6 & Unknown expressed protein \\
\hline AK107941 & 1.0 & 1.1 & 1.5 & 2.3 & 1.1 & 1.1 & 2.9 & 4.9 & Unknown expressed protein \\
\hline AK101427 & 1.1 & 1.1 & 1.2 & 2.2 & 1.0 & 1.2 & 2.3 & 5.0 & Aldehyde dehydrogenase RF2D \\
\hline AK111613 & 1.0 & 0.9 & 1.2 & 2.4 & 1.0 & 1.0 & 3.5 & 4.9 & Phosphatidylinositol 3-kinase \\
\hline AK107839 & 1.0 & 0.7 & 1.3 & 4.7 & 0.9 & 1.3 & 8.8 & 18.0 & Unknown expressed protein \\
\hline AK066495 & 1.2 & 0.9 & 2.2 & 2.3 & 1.2 & 2.2 & 5.5 & 7.5 & OsCDPK 7 \\
\hline AK111302 & 0.8 & 1.1 & 1.6 & 5.0 & 1.0 & 1.9 & & 17.0 & Unknown expressed protein \\
\hline AK107990 & 1.0 & 1.2 & 1.9 & 4.2 & 1.0 & 1.1 & 3.4 & 10.4 & Unknown expressed protein \\
\hline AK069266 & 1.3 & 1.4 & 2.0 & 2.1 & 1.2 & 1.7 & 3.2 & 4.2 & Gibberellin-responsive protein \\
\hline AK062604 & 1.2 & 1.0 & 2.3 & 2.2 & 0.8 & 1.5 & 3.0 & 4.0 & Unknown expressed protein \\
\hline AK062877 & 0.8 & 0.8 & 0.8 & 2.7 & 0.9 & 1.0 & 6.6 & 4.5 & Unknown expressed protein \\
\hline AK063833 & 0.9 & 1.1 & 1.2 & 21.3 & 1.0 & & 4.0 & 75.3 & Subtilisin-chymotrypsin inhibitor \\
\hline AK062139 & 0.9 & 0.8 & 2.2 & 2.5 & 1.0 & 1.4 & 1.0 & 4.0 & AAA-ATPase-like protein \\
\hline AK101390 & 0.9 & 1.0 & 1.4 & 4.1 & 0.8 & 0.9 & 4.1 & 10.7 & Unknown expressed protein \\
\hline AK067007 & 0.8 & 0.9 & 1.3 & 2.9 & 1.1 & 1.0 & 3.3 & 5.4 & Cytochrome $\mathrm{P} 450$ protein \\
\hline AK101767 & 1.1 & 0.9 & 1.2 & 2.5 & 1.0 & 0.9 & 2.7 & 4.2 & Unknown expressed protein \\
\hline AK107848 & 1.0 & 1.4 & 1.5 & 2.5 & 0.8 & 1.4 & 3.3 & 4.9 & Copper transporter protein \\
\hline AK065930 & 1.0 & 1.3 & 1.0 & 2.2 & 1.0 & 1.0 & 3.8 & 4.9 & Unknown expressed protein \\
\hline AK065416 & 1.0 & 0.9 & 0.9 & 3.0 & 1.8 & 0.9 & 2.2 & 9.1 & Unknown expressed protein \\
\hline AK059727 & 1.8 & 1.1 & 0.6 & 2.9 & 1.4 & 0.8 & 3.8 & 8.5 & Protein kinase \\
\hline AK063625 & 1.4 & 1.2 & 1.4 & 10.6 & 0.9 & 1.4 & 5.0 & 30.2 & Caleosin \\
\hline AK063133 & 1.4 & 1.0 & 1.1 & 8.2 & 1.2 & 1.1 & 3.2 & 19.7 & Unknown expressed protein \\
\hline AK109096 & 1.4 & 1.4 & 1.8 & 2.1 & 1.1 & 1.4 & 2.5 & 8.1 & Dehydrin \\
\hline AK062588 & 1.1 & 1.1 & 1.6 & 8.2 & 0.8 & 1.4 & 4.7 & 19.4 & Unknown expressed protein \\
\hline AK105051 & 0.8 & 1.0 & 0.7 & 2.1 & 1.3 & 0.6 & 2.5 & 10.1 & Thioredoxin \\
\hline
\end{tabular}


Table 2. Continued.

\begin{tabular}{|c|c|c|c|c|c|c|c|c|c|}
\hline \multirow{2}{*}{ Accession } & \multicolumn{4}{|c|}{$\Delta$ fla-N1141 } & \multicolumn{4}{|c|}{ N1141 } & \multirow{2}{*}{ Putative gene identification } \\
\hline & $0 \mathrm{~h}$ & $1 \mathrm{~h}$ & $3 \mathrm{~h}$ & $6 \mathrm{~h}$ & $0 \mathrm{~h}$ & $1 \mathrm{~h}$ & $3 \mathrm{~h}$ & $6 \mathrm{~h}$ & \\
\hline AK111773 & 1.1 & 0.9 & 0.9 & 10.3 & 1.1 & 1.0 & 5.6 & 46.3 & Seven transmembrane protein Mlo9 \\
\hline AK063747 & 1.2 & 0.8 & 1.3 & 6.9 & 1.0 & 1.7 & 4.2 & 37.1 & Unknown expressed protein \\
\hline AK063913 & 1.0 & 0.8 & 1.7 & 4.8 & 1.1 & 1.1 & 2.4 & 11.0 & Glutamine synthetase \\
\hline AK111548 & 1.0 & 1.1 & 1.0 & 2.0 & 1.0 & 1.1 & 3.6 & 4.3 & Unknown expressed protein \\
\hline AK069814 & 1.0 & 0.8 & 1.2 & 29.3 & 1.1 & 1.0 & 22.4 & 64.1 & Unknown expressed protein \\
\hline AK059799 & 1.1 & 1.1 & 1.6 & 2.1 & 0.9 & 1.1 & 2.2 & 5.1 & Zm-Rab2-B GTP binding protein \\
\hline AK100429 & 1.0 & 0.9 & 0.9 & 5.6 & 1.1 & 0.8 & 3.8 & 15.4 & Unknown expressed protein \\
\hline AK063206 & 0.9 & 1.0 & 1.9 & 3.1 & 1.1 & 0.8 & 1.7 & 8.1 & Unknown expressed protein \\
\hline AK068117 & 1.2 & 1.5 & 1.4 & 5.9 & 1.1 & 1.1 & 13.5 & 17.9 & Unknown expressed protein \\
\hline AK107721 & 1.1 & 1.3 & 0.8 & 2.2 & 1.0 & 1.4 & 3.1 & 8.1 & Unknown expressed protein \\
\hline AK107654 & 1.3 & 1.0 & 0.9 & 2.3 & 1.0 & 1.5 & 2.1 & 24.3 & LEA protein \\
\hline AK106851 & 1.0 & 1.3 & 0.4 & 6.8 & 1.0 & 0.7 & 9.6 & 25.0 & POPCEL2 \\
\hline AK067988 & 1.1 & 1.1 & 1.2 & 2.6 & 1.0 & 1.1 & 2.4 & 6.9 & Hexokinase 1 \\
\hline AK111503 & 1.0 & 1.2 & 1.2 & 3.2 & 1.0 & 1.3 & 2.9 & 6.1 & RNA-binding protein MEI2 \\
\hline AK109177 & 1.0 & 0.9 & 1.5 & 2.1 & 1.1 & 2.2 & 0.4 & 7.9 & Oshox6 \\
\hline AK071762 & 1.1 & 1.1 & 1.0 & 21.2 & 1.1 & 0.9 & 10.2 & 52.6 & Unknown expressed protein \\
\hline AK073738 & 1.1 & 1.2 & 0.9 & 2.3 & 0.9 & 0.8 & 3.6 & 5.9 & NADPH-dependent oxidoreductase \\
\hline AK070825 & 0.9 & 1.1 & 1.3 & 10.4 & 1.2 & 0.9 & 2.9 & 31.1 & Unknown expressed protein \\
\hline AK110542 & 1.0 & 1.1 & 1.1 & 8.9 & 1.1 & 0.9 & 2.0 & 23.9 & Glucan endo-1,3-beta-glucosidase \\
\hline AK065286 & 1.1 & 1.0 & 1.2 & 19.6 & 1.2 & 1.1 & 6.0 & 40.0 & Amino acid transporter \\
\hline AK100299 & 1.0 & 0.9 & 1.9 & 4.1 & 1.0 & 1.1 & 3.4 & 10.2 & Unknown expressed protein \\
\hline AK067957 & 0.8 & 1.4 & 1.4 & 2.6 & 0.9 & 1.4 & 3.0 & 3.8 & Protein kinase \\
\hline AK071623 & 0.9 & 0.7 & 1.9 & 2.5 & 1.1 & 1.3 & 1.1 & 4.7 & Amino acid or GABA permease \\
\hline AK063682 & 1.1 & 0.8 & 0.6 & 3.4 & 1.2 & 0.9 & 3.2 & 10.7 & Unknown expressed protein \\
\hline AK111545 & 1.2 & 1.1 & 0.9 & 10.7 & 1.4 & 1.1 & 3.3 & 19.0 & HR-induced response protein \\
\hline AK111617 & 1.4 & 1.3 & 1.3 & 3.9 & 1.1 & 1.7 & 3.5 & 9.8 & Unknown expressed protein \\
\hline
\end{tabular}

present in a wide range of land plants. It has been reported that 75 and $105 N A C$ genes were predicted in rice and Arabidopsis genomes, respectively (Ooka et al. 2003). Therefore, expression profiles of some OsNAC family genes were analyzed during HR cell death using real-time RT-PCR. We selected six OsNAC genes (OsNAC3, OsNAC4, OsNAC5, OsNAC6, OsNAC7 and OsNAC8) and synthesized each specific primer set. Cultured rice cells were inoculated with the incompatible N1141 strain of $A$. avenae, and total RNA was extracted $0,1,3$ and $6 \mathrm{~h}$ after inoculation. The OsNAC4 transcript was found to be induced $3 \mathrm{~h}$ after incubation with the N1141 strain, and expression levels at $6 \mathrm{~h}$ after inoculation reached 30 -fold compared to that at before inoculation (Figure 3). In addition, expression levels of $O s N A C 3$ and OSNAC6 were slightly increased $6 \mathrm{~h}$ after the inoculation, whereas no mRNA increases of OSNAC5, OsNAC7 and OSNAC8 were observed (Figure 3). The data indicate that among the analyzed genes, expression level of OSNAC4 was greatly increased by inoculation of the incompatible N1141 strain. To confirm whether induction of the OSNAC4 mRNA depends on HR cell death induction, cultured rice cells were inoculated with the incompatible N1141 strain and flagellin-deficient strains ( $\Delta$ fla-N1141) and expression patterns of OSNAC4 were analyzed by real-time RT-PCR. The inoculation of cultured rice cells with $\triangle$ fla-N1141 strain failed to cause activation of OsNAC4 mRNA expression, suggesting that induction of

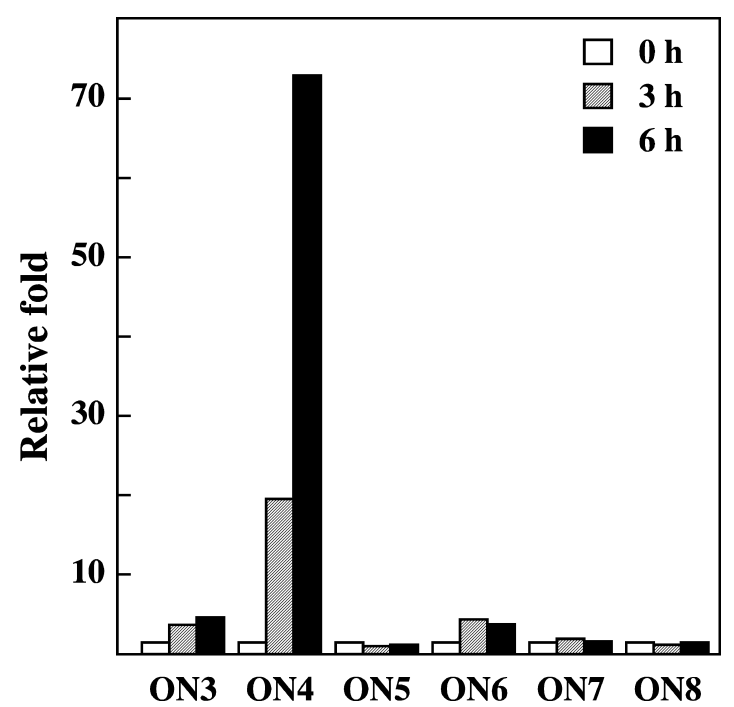

Figure 3. Expression patterns of several $O S N A C$ genes in cultured rice cells inoculated with the incompatible N1141 strain. The amount of each mRNA was calculated from the threshold point located in the log-linear range of RT-PCR. Standard samples with known template amounts were used for quantification of each mRNA. The y axis represents fold change relative to the amount of mRNA in water-treated cultured rice cells. Open column, $0 \mathrm{~h}$ after N1141 inoculation; hatched column, $3 \mathrm{~h}$ after N1141 inoculation; solid column, $6 \mathrm{~h}$ after N1141 inoculation. ON3, OsNAC3; ON4, OsNAC4; ON5, OsNAC5; ON6, OsNAC6; ON7, OsNAC7; ON8, OsNAC8. 


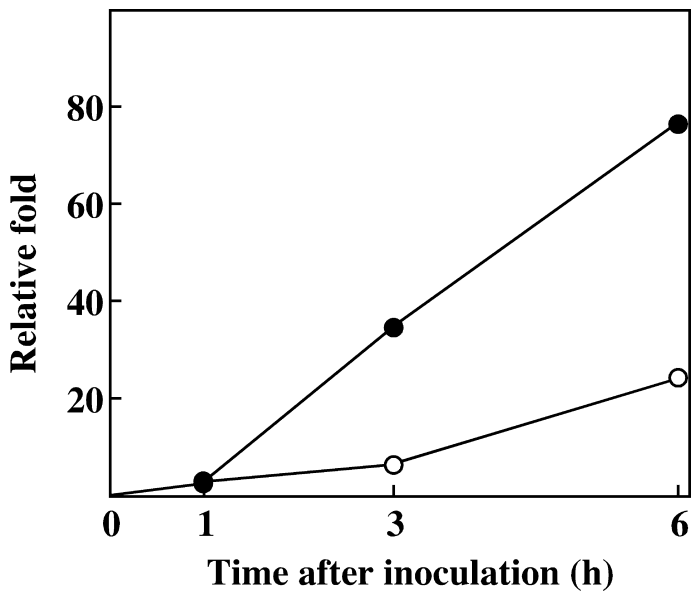

Figure 4. Expression patterns of OsNAC4 genes in cultured rice cells inoculated with the incompatible N1141 strain (solid circles) and the flagella-deficient $\Delta$ fla-N1141 strain (open circles). The amount of each mRNA was calculated from the threshold point located in the log-linear range of RT-PCR. Standard samples with known template amounts were used for quantification of each mRNA. The y axis represents fold change relative to the amount of mRNA in water-treated cultured rice cells.

OsNAC4 is involved in HR cell death induction (Figure 4). OsNAC4 would be the important factor for triggering or execution of HR cell death.

\section{Discussion}

Although HR cell death is one of the important type of programmed cell death in plants, detailed molecular description of HR cell death program has remained elusive. In this paper, we demonstrated that gene expression and protein phosphorylation cascade are essential for induction of HR cell death. Furthermore, we identified genes which are specifically induced during HR cell death using PCR subtraction and microarray analysis. Among the identified genes, OsNAC4 appears to be a convincing candidate as an initiation factor for HR cell death induction.

Plant immune response requires a rapid protein phosphorylation cascade for its own coordinated processes (Zhang et al. 2002). Inhibitors of protein kinases and phosphatases are useful tools to investigate the role of phosphoproteins in signal transduction. This pharmacological approach repeatedly has demonstrated that changes in protein phosphorylation regulate diverse cellular processes including some plant defense responses (Romeis 2001). It has been reported that several elicitors such as flagellin and chitin could induce protein phosphorylation in Arabidopsis thaliana and cultured rice cells (Peck et al. 2001; Zhang et al. 2002). Similarly, addition of protein kinase inhibitors blocks the early defense responses, and phosphatase inhibitors induce many of the same responses induced by microbial elicitors (Scheel 1998; McDowell and Dangl 2000; Peck
2001). In our experiments, staurosporine and K252a effectively suppressed HR cell death induction in culture rice cells, whereas calyculin A and okadaic acid did not inhibit induction of HR cell death in cultured rice cells inoculated with the incompatible N1141 strains. Calyculin A and okadaic acid are potent inhibitors of serine/threonine phosphatases, while staurosporine and K252a are strong inhibitors of serine/threonine kinase in plants and animals. This is good evidence that HR cell death requires protein phosphorylation mediated by several protein kinases for HR cell death in plants. Members of different protein kinase subfamilies, such as calcium-dependent protein kinase (CDPKs) and MAP kinases, play an essential role in the plant defense response (Romeis 2001). Changes in cytoplasmic calcium concentration are one of the earliest cellular responses to stress stimuli, and CDPKs may function as sensors for this change (Harmon et al. 2000). Interestingly, our microarray analysis revealed that OsCDPK7 was specifically induced more than 7-fold upon HR cell death. OsCDPK7 may be involved in the induction of HR cell death.

NAC family proteins have a consensus sequence known as the NAC domain (petunia NAM and Arabidopsis $\underline{\text { ATAF1 }}$ and $\mathrm{CUC2}$ ) that is located in the $\mathrm{N}$-terminal region and is divided into five subdomains. The finding that petunia plants with mutated NAM genes failed to form shoot apical meristems indicates that NAM plays a role in determining the position of the shoot apical meristem and primordial in this plant (Souer et al. 1996). Similarly, mutated CUC2 causes defects in the separation of cotyledons, sepals and stamens, as well as in the formation of the shoot apical meristem (Aida et al. 1999). Moreover, NAC1 is induced by auxin and mediates auxin signaling to promote lateral root development (Xie et al. 2000) and NAP is involved in controlling cell expansion of specific flower organs (Sablowski and Meyerowitz 1998). These observations indicate that some of the NAC family proteins are involved in various plant developmental and morphogenic systems. More recently, a few $N A C$ genes, such as AtNAC072 (RD26), AtNAC019 and AtNAC055 from Arabidopsis (Fujita et al. 2004), and BnNAC from Brassica (Hegedus et al. 2003), were found to be involved in the response to various environmental stresses. However, the function of other NAC proteins is not clear.

Analysis of the alignment of proteins with NAC domains showed that the proteins constituted a large family, which could be classified into two groups and 18 subgroups (Ooka et al. 2003). In this experiment, we have shown that among six $O S N A C$ genes, expression of $O S N A C 4$ was greatly induced during HR cell death, and expression levels of $O S N A C 3$ and $O S N A C 6$ were slightly increased (Figure 3). Interestingly, OsNAC4 and 
OsNAC3 are classified in the same category, the OsNAC3 subfamily. Although this subfamily consists of 9 proteins, the biological functions of NAC proteins belonging to it are still not known. Several NAC proteins which belong to this subfamily would be involved in plant immune responses including HR cell death. OsNAC6 is classified in the ATAF subfamily (Ooka et al. 2003). It is known that ATAF1, ATAF2, and stNAC, which belong to the ATAF subfamily, are rapidly and transiently induced by environmental stresses such as wounding. NAC protein in the ATAF subfamily has motif V. These reports and results provide strong support for the idea that the NAC family members in subgroup ATAF share a conserved role in the response to stress stimuli. In fact, OsNAC6 is induced by cold, salt, drought and wounding (Ohnishi et al. 2005). Induction of OsNAC6 might be triggered by wounding signal with bacterial contact rather than the incompatible interaction, because no OsNAC6 clone was obtained in comparative microarray analysis for comparison between N1141 and $\Delta$ fla-N1141 interactions (Table 2).

Although OsNAC4 is induced during HR cell death, it is not clear whether it is the most important factor for initiation of HR cell death. Studies of overexpression or suppression of OSNAC4 using transgenic rice plants are useful to clarify the role of OsNAC4 in plant HR induction. Further studies are needed to determine whether OSNAC4 is truly involved in the induction of $\mathrm{HR}$ cell death.

\section{Acknowledgments}

We are grateful to Eriko Okamoto for excellent technical support. This work was supported in part by Grants-in-Aid for Scientific Research (B) (17380067) and Creative Scientific Research (16GS0316 to A.I.) from the Ministry of Education, Culture, Sports, Science, and Technology, Japan.

\section{References}

Agrios GN (1997) How plants defend themselves against pathogens. In: Agrios GN (ed). Plant Pathology 4th Edition, Academic Press Sandiego, pp 93-114

Aida M, Ishida T, Tasaka M (1999) Shoot apical meristem and cotyledon formation during Arabidopsis embryogenesis: interaction among the CUP-SHAPED COTYLEDON and SHOOT MERISTEMLESS genes. Development 126: 15631570

Akimoto-Tomiyama C, Sakata K, Yazaki J, Nakamura K, Fujii F, Shimbo K, Yamamoto K, Sasaki T, Kishimoto N, Kikuchi S, Shibuya N, Minami E (2003) Rice gene expression in response to N-acetylchitooligosaccharide elicitor: comprehensive analysis by DNA microarray with randomly selected ESTs. Plant Mol Biol 52: 537-551

Alvarez ME, Pennell RI, Meijer PJ, Ishikawa A, Dixon RA, Lamb C (1998) Reactive oxygen intermediates mediate a systemic signal network in the establishment of plant immunity. Cell 92:
773-784

Baba A, Hasezawa S, Syono K (1986) Cultivation of rice protoplasts and their transformation mediated by Agrobacterium spheroplasts. Plant Cell Physiol 27: 463-472

Bolwell GP, Butt VS, Davies DR, Zimmerlin A (1995) The origin of the oxidative burst in plants. Free Radic Res 23: 517-532

Che FS, Iwano M, Tanaka N, Takayama S, Minami E, Shibuya N, Kadota I, Isogai A (1999) Biochemical and morphological features of rice cell death induced by Pseudomonas avenae. Plant Cell Physiol 40: 1036-1045

Che FS, Nakajima Y, Tanaka N, Iwano M, Yoshida T, Takayama S, Kadota I, Isogai A (2000) Flagellin from an incompatible strain of Pseudomonas avenae induces a resistance response in cultured rice cells. J Biol Chem 275: 32347-32356

Corbin DR, Sauer N, Lamb CJ (1987) Differential regulation of a hydroxyproline-rich glycoprotein gene family in wounded and infected plants. Mol Cell Biol 7: 4337-4344

Dangl JL, Jones JD (2001) Plant pathogens and integrated defence responses to infection. Nature 411: 826-833

Dietrich RA, Richberg MH, Schmidt R, Dean C, Dangl JL (1997) A novel zinc finger protein is encoded by the Arabidopsis LSDI gene and functions as a negative regulator of plant cell death. Cell 88: 685-694

Dixon RA, Harrison MJ, Lamb CJ (1994) Early events in the activation of plant defense responses. Annu Rev Phytopathol 32: 479-501

Fujita M, Fujita Y, Maruyama K, Seki M, Hiratsu K, Ohme-Takagi M, Tran LS, Yamaguchi-Shinozaki K, Shinozaki K (2004) A dehydration-induced NAC protein RD26 is involved in a novel ABA-dependent stress-signaling pathway. Plant J 39: 863-876

Gilchrist DG (1998) Programmed cell death in plant disease: the purpose and promise of cellular suicide. Annu Rev Phytopathol 36: 393-414

Gray J, Johal GS (1998) Programmed cell death in plants. In Anderson M, Roberts JA (eds). Arabidopsis, Sheffield UK, Sheffield Academic Press, pp 360-394

Greenberg JT (1997) Programmed cell death in plant-pathogen interactions. Annu Rev Plant Physiol Plant Mol Biol 48: 525545

Greenberg JT, Yao N (2004) The role and regulation of programmed cell death in plant-pathogen interactions. Cell Microbiol 6: 201-211

Hardwick JS, Kuruvilla FG, Tong JK, Shamji AF, Schreiber SL (1999) Rapamycin-modulated transcription defines the subset of nutrient-sensitive signaling pathways directly controlled by the Tor proteins. Proc Natl Acad Sci USA 96: 14866-14870

Harmon AC, Gribskov M, Harper JF (2000) CDPKs - a kinase for every $\mathrm{Ca}^{2+}$ signal? Trends Plant Sci 5: 154-159

He SY (1996) Elicitation of Plant Hypersensitive Response by Bacteria. Plant Physiol 112: 865-869

Heath MC (1998) Apoptosis programmed cell death and hypersensitive response. Eur J Plant Pathol 104: 117-124

Heath MC (2000) Non-host resistance and non-specific plant defenses. Curr Opin Plant Biol 3: 315-319

Hegedus D, Yu M, Baldwin D, Gruber M, Sharpe A, Parkin I, Whitwill S, Lydiate D (2003) Molecular characterization of Brassica napus NAC domain transcriptional activators induced in response to biotic and abiotic stress. Plant Mol Biol 53: 383-397

Jabs T, Dietrich RA, Dangl JL (1996) Initiation of runaway cell death in an Arabidopsis mutant by extracellular superoxide. Science 273: 1853-1856 
Kadota I, Mizuno A, Nishiyama K (1996) Detection of a protein specific to the strain of Pseudomonas avenae Manns 1909 pathogenic to rice. Ann Phytopathol Soc Jpn 62: 425-428

Kadota I, Ohuchi A, Nishiyama K (1991) Serological properties and specificity of Pseudomonas avenae Manns 1909 the causal agent of bacterial brown stripe of rice. Ann Phytopathal Soc Jpn 57: 268-273

Kutuk O, Basaga H (2006) Bcl-2 protein family: Implications in vascular apoptosis and atherosclerosis. Apoptosis 11: 16611675

Lacomme C, Santa Cruz S (1999) Bax-induced cell death in tobacco is similar to the hypersensitive response. Proc Natl Acad Sci USA 96: 7956-7961

Lam E (2004) Controlled cell death plant survival and development. Nat Rev Mol Cell Biol 5: 305-315

Lamb C, Dixon RA (1997) The oxidative burst in plant disease response. Annu Rev Plant Physiol Plant Mol Bio 48: 251-275

Levine A, Pennell RI, Alvarez ME, Palmer R, Lamb C (1996) Calcium-mediated apoptosis in a plant hypersensitive disease resistance response. Curr Biol 6: 427-437

McDowell JM, Dangl JL (2000) Signal transduction in the plant immune response. Trends Biochem Sci 25: 79-82

Mittler R, Lam E (1996) Sacrifice in the face of foes: pathogeninduced programmed cell death in plants. Trends Microbiol 4: $10-15$

Morel JB, Dangl JL (1997) The hypersensitive response and the induction of cell death in plants. Cell Death Differ 4: 671-683

Nimchuk Z, Eulgem T, Holt BF 3rd, Dangl JL (2003) Recognition and response in the plant immune system. Annu Rev Genet 37: 579-609

Nishiyama K, Nishihara N, Ezuka A (1979) Bacterial brown stripe of ragi caused by Pseudomonas alboprecipitans. Ann Phytopathol Soc Jpn 45: 25-31

Ohnishi T, Sugahara S, Yamada T, Kikuchi K, Yoshiba Y, Hirano HY, Tsutsumi N (2005) OsNAC6, a member of the NAC gene family, is induced by various stresses in rice. Genes Genet Syst 80: 135-139

Ooka H, Satoh K, Doi K, Nagata T, Otomo Y, Murakami K, Matsubara K, Osato N, Kawai J, Carninci P, Hayashizaki Y, Suzuki K, Kojima K, Takahara Y, Yamamoto K, Kikuchi S (2003) Comprehensive analysis of NAC family genes in Oryza sativa and Arabidopsis thaliana. DNA Res 10: 239-247
Peck SC, Nuhse TS, Hess D, Iglesias A, Meins F, Boller T (2001) Directed proteomics identifies a plant-specific protein rapidly phosphorylated in response to bacterial and fungal elicitors. Plant Cell 13: 1467-1475

Pennell RI, Lamb C (1997) Programmed Cell Death in Plants. Plant Cell 9: 1157-1168

Richberg MH, Aviv DH, Dangl JL (1998) Dead cells do tell tales. Curr Opin Plant Biol 1: 480-485

Romeis T (2001) Protein kinases in the plant defense response. Curr Opin Plant Biol 4: 407-414

Sablowski RW, Meyerowitz EM (1998) A homolog of NO APICAL MERISTEM is an immediate target of the floral homeotic genes APETALA3/PISTILLATA. Cell 92: 93-103

Scheel D (1998) Resistance response physiology and signal transduction. Curr Opin Plant Biol 1: 305-310

Shi Y (2002) Mechanisms of caspase activation and inhibition during apoptosis. Mol Cell 9: 459-470

Souer E, van Houwelingen A, Kloos D, Mol J, Koes R (1996) The no apical meristem gene of Petunia is required for pattern formation in embryos and flowers and is expressed at meristem and primordia boundaries. Cell 85: 159-170

Tanaka N, Nakajima Y, Kaneda T, Takayama S, Che FS, Isogai A (2001) DNA laddering during hypersensitive cell death in cultured rice cells induced by an incompatible strain of Pseudomonas avenae. Plant Biotechnol 18: 295-299

Torii KU (200) Receptor kinase activation and signal transduction in plants: an emerging picture. Curr Opin Plant Biol 3: 361367

Xie Q, Frugis G, Colgan D, Chua NH (2000) Arabidopsis NAC1 transduces auxin signal downstream of TIR1 to promote lateral root development. Genes Dev 14: 3024-3036

Xu P, Roossinck MJ (2000) Cucumber mosaic virus D satellite RNA-induced programmed cell death in tomato. Plant Cell 12: 1079-1092

Yao N, Tada Y, Park P, Nakayashiki H, Tosa Y, Mayama S (2001) Novel evidence for apoptotic cell response and differential signals in chromatin condensation and DNA cleavage in victorin-treated oats. Plant J 28: 13-26

Zhang B, Ramonell K, Somerville S, Stacey G (2002) Characterization of early chitin-induced gene expression in Arabidopsis. Mol Plant Microbe Interact 15: 963-970 